\title{
O CREPÚSCULO DA REPRESENTAÇÃo NA PRÁTICA CIENTÍFICA
}

\section{THE TWILIGHT OF REPRESENTATION IN SCIENTIFIC PRACTICE}

\author{
João Victor de Farias e Nascimento ${ }^{1}$ \\ (farianascimentoj@gmail.com)
}

\begin{abstract}
RESUMO
Não há sentido em uma ciência que tente inferir no objeto com mínima intervenção possível: a partir dessa simples proposição, este artigo pretende analisar, talvez em mais tópicos do que poderia por si só tragar, o sentido da representação tal como usado na tradição e sua respectiva superação em prol do que Ian Hacking nomeia realismo ontológico ou realismo de entidades. Representações, necessárias para a investigação do objeto, são cognoscíveis mesmo que não seja possível responder a elas adequadamente na própria natureza da linguagem. Pode-se, então, questionar a necessidade de permanecer o papel essencial da investigação da representação na prática científica, tal como levado a cabo nos embates entre o realismo e o antirrealismo na filosofia contemporânea.
\end{abstract}

Palavras-chave: Ciência. Representação. Realismo.

\begin{abstract}
There is no sense in a science who tries to infer in the object interfering as little as possible: from this simple proposition, this article intends to analyze, perhaps in more topics than it could swallow, the sense of representation as used in the tradition, and its respective overcoming in favor of what Ian Hacking names ontological realism or entity realism. Representations, necessary elements for the investigation of the object, are knowable even if it's not possible to answer them adequately in the very nature of language. It becomes possible to question the need of the essential role of the investigation of representation in scientific practice, as it is done in the clashes between realism and anti-realism in contemporary philosophy.
\end{abstract}

Keywords: Science. Representation. Realism.

\section{INTRODUÇÃO}

Genericamente, a intuição mais precisa de uma representação se traduz pela faculdade subjetiva a priori de o sujeito tomar conhecimento do mundo e dos objetos que o rodeiam

\footnotetext{
${ }^{1}$ Graduando em Filosofia pela Universidade de Brasília (UnB).

Lattes: http://lattes.cnpq.br/6521813585174451.

ORCID: https://orcid.org/0000-0001-5416-8966.
} 
(BRANQUINHO; MURCHO; GOMES, 2005, p. 689). Toda relação semiótica de representação é mediada por um sujeito em uma relação triádica entre mundo, linguagem e mente. Segundo C. S. Peirce (1839 -1914), qualquer relação estipula a priori um sujeito interpretante que representa, i.e., que, imerso na ordem do mental, relaciona um $a$ que representa $b$ para um sujeito $c$. Pelo caráter inerentemente subjetivo que acarreta qualquer representação, a tendência da filosofia contemporânea da linguagem foi restringir a representação a mero conceito operatório de uma relação triádica (BRANQUINHO; MURCHO; GOMES, loc. cit.).

Essa tradição, tendo por um lado o pragmatismo, de que Peirce é parte, articula o concebível no próprio processo de conhecimento (HACKING, 2012, p. 134) e, tendo por outro lado toda a tradição do positivismo lógico, nega a possibilidade de fundamentação da causação e restringe o real ao observável (HACKING, loc. cit.). Todavia, ambos os lados, independentemente de suas discrepâncias, concordam com que toda e qualquer carga de subjetividade aliada a conceitos não pode pretender descrever leis objetivas, nem as do pensamento nem as das coisas tal como elas são, restringindo a representação a uma espécie de mentalismo.

$\mathrm{Na}$ ordem da linguagem, apenas proposições declarativas dotadas de sentido carregam consigo a ordem do público, podendo ser julgadas apropriadamente sem aquele subjetivismo que torna o sentido naturalmente incomunicável (LECOURT, 2018, p. 57-58). Contrária ao regime dessas proposições e frases declaratórias na ordem do público está a representação [Vorstellung], que, nessa tradição, é reduzida intransponivelmente à ordem do privado ordem intransmissível e não declaratória -, reduzindo-se o campo de ação das ciências.

A conclusão do devido lugar da representação traz consequências muito relevantes para a teoria da verdade contemporânea (LECOURT, 2018, p. 55) juntamente ao desenvolvimento da ciência, a ponto de exigir grande esforço de Ian Hacking na crítica que estrutura ao antirrealismo, bem como na designação de seu lugar: admitindo-se a representação na ordem do privado, ou a representação traz consigo algo de incomunicável em relação à totalidade do objeto representado, ou a adequação é total, de modo que não há diferença entre representação e representado. No que se refere ao último caso, em Peirce, admitir a totalidade da comunicação entre representação e representado é contrariar a exigência do conceito privativo inerente à representação. $O$ pensamento verdadeiro, em Frege, não exige um portador, i.e., não exige uma mente subjetiva pensante que assegure a verdade do pensamento tal como a res cogitans cartesiana, pois o pensamento, 
enquanto na ordem do público, é apenas a asserção de um sentido verdadeiro ou falso que independente de uma mente pensante que anteceda as condições de verdade da proposição. Se a filosofia pretende a si mesma descrever leis objetivas e, em última instância, a objetividade de todo ser verdadeiro, dificilmente a representação poderá continuar a ser, nessa perspectiva, algo relevante à filosofia (BRANQUINHO; MURCHO; GOMES, 2005, p. 690), devendo ser suprimida, ao menos em seu uso prático-operatório, a uma linguagem que possa traduzir a verdade de forma objetiva.

Todo pensamento ou proposição, portanto, deve ter em vista seu uso assertivo e público conforme sua natureza impessoal, que apreende o sentido de uma proposição e concebe no entendimento suas condições de verdade ou falsidade. Uma vez apreendido o sentido de uma proposição e as condições de sua verdade, é irrelevante conhecer o pensamento de quem a redigiu. Em suma, todo o problema em admitir a subjetividade do pensamento e a relevância da representação consiste em que, se o pensamento fosse de fato absolutamente interior no mesmo nível da representação, do mesmo modo a verdade do pensamento teria de se fundamentar em relação a algo que não fosse absolutamente pensamento. Toda vez que se indagasse se uma relação é de fato verdadeira, a pergunta seguinte seria por como se dá a relação entre uma verdade não absolutamente espiritual e a realidade puramente subjetiva do pensamento. Em suma, uma vez admitida a assertividade da verdade de uma proposição, o questionamento seria se era precisamente verdadeiro o pensamento nessa relação, uma vez que a verdade não pode se dar externamente ao pensamento - isso, em última instância, é recair em contradições insustentáveis nas quais, toda vez que se exigisse a verdade de uma proposição, a assertividade não se dirigiria mais à proposição mesma, mas à mente inteligível do portador da asserção.

A respectiva diminuição epistemológica da representação e a prioridade de expressões proposicionais da linguagem como único valor de verdade acessível ao entendimento é uma característica talvez irreversível da filosofia contemporânea (BRANQUINHO; MURCHO; GOMES, 2005, p. 692). Apesar do perigo de se reduzir a representação inteiramente à esfera subjetiva - uma redução psicologizante que não consegue lidar mais com qualquer verdade e que, enquanto objeto de estudo da filosofia da ciência, está diretamente imersa, em um primeiro momento, nas discussões do realismo científico -, a própria tradição não só define bem a indissociabilidade do conceito de representação de sua respectiva expressão linguística, como também nunca separou a representação do juízo. Se por um lado a ascensão abrupta das ciências naturais quebrou o raciocínio retilíneo ocidental para 
substituir sua episteme pelo espírito do progresso, isso não se deu sem a descoberta cruel de que os sentidos, por si mesmos, não podem traduzir a verdade exigida pelo entendimento, e de que não há método não humano para definir a realidade. Hannah Arendt resume excelentemente todo o problema aqui proposto:

Descartes tornou-se o pai da Filosofia moderna por ter generalizado a experiência da geração precedente bem como a da sua, desenvolvendo-a em um novo método de pensar e tornando-se dessa forma o primeiro pensador integralmente treinado nesta "escola de suspeita" que, segundo Nietzsche, constitui a Filosofia moderna. A suspeita dos sentidos permaneceu o cerne do orgulho científico, até se tornar, em nossos dias, uma fonte de embaraço. [...] O problema, em outras palavras, não está em que o universo físico moderno não possa ser visualizado, pois isto é uma consequência lógica do pressuposto de que a natureza não se revela aos sentidos humanos; o embaraço começa quando a natureza se evidencia inconcebível, isto é, impensável igualmente em termos de puro raciocínio. (ARENDT, 2018, p. 86)

\section{REPRESENTAÇÃO NA TRADIÇÃO \& ENQUANTO FENÔMENO}

Quando Kant sugere clarificar a faculdade do entendimento, ele não propõe uma análise de como se dão suas relações ou a decomposição do que se entende enquanto tal - já notoriamente estudadas pela lógica -, mas como se dá a faculdade do entendimento por meio de conceitos do entendimento, assimilados como germes que só florescerão na experiência e nas faculdades que a estética transcendental lhes fornece. $\mathrm{O}$ entendimento, por sua vez, não participa de intuição alguma e, fora dela, o único modo de conhecer é precisamente por meio de conceitos (KANT, 1997, A68). Esses conceitos tampouco podem participar das faculdades de intuição, de modo que o conceito nada intui, sendo apenas discursivo (KANT, 1997, A68/B93). Enquanto representação de fenômenos, o conceito remete ou ao objeto ou a outro conceito no entendimento. Os juízos surgem como faculdades que medeiam conceitos, representações de representações, sendo assim produto próprio à faculdade do entendimento de regular os mais variados conceitos existentes, sendo eles funções da unidade das representações (KANT, 1997, B94). Dada a propensão da mente humana a buscar uma ordem necessária nas representações dos fenômenos, o entendimento formula juízos como unidades mediatas e elevadas das representações e constitui a própria ação do entendimento como faculdade de julgar. 
Ainda que vivamos em um universo de acaso - tal como postula Peirce, indeterminístico em seus fundamentos (HACKING, 2012, p. 131) -, o pragmatista admite a habilidade humana de realizar concepções mais ou menos certas sobre o mundo (HACKING, 2012, p. 126). Nessa perspectiva, o mundo é regido por procedimentos de formação de hábitos: os hábitos que cada sujeito infere a respeito das coisas são formados pelas mesmas regularidades de que o mundo pensado se formou antes do sujeito. Na opinião de Hacking, trata-se de uma conjectura metafísica no mínimo bizarra, mas que ao menos justifica em certa medida o sucesso das explicações da constituição interna da natureza. Ainda em Kant, independentemente de haver, de fato, uma natureza discordante o suficiente de modo que cada elemento detenha uma categoria que lhe é própria, sem possibilidade de generalizações ou explicação para todas essas representações, ainda assim o princípio lógico supõe uma ordem necessária aos objetos que nos são representados. É justamente por um princípio transcendental que aplique às representações uma ordem não dada a priori, mas necessária para a unidade dos conceitos, que há condição para a exigência de uma ideia reguladora constitutiva dos fenômenos e, mais além, para a constituição de uma ciência.

Talvez como uma ironia a qualquer um que queira entender melhor a noção de representação em Ian Hacking, logo no início do capítulo "Realismo interno", em que o autor expõe o pensamento de Putnam, ele admite que, para os demais tópicos referentes ao realismo científico, aquele capítulo é inútil (HACKING, 2012, p. 167). Poder-se-ia pensar que a transição de uma perspectiva idealista para uma realista seria central para a discussão da atividade científica, mas Hacking é lacônico ao afirmar que não. Uma filosofia alicerçada em reflexões acerca da linguagem nunca pode dizer nada de positivo sobre a ciência, Hacking afirma referindo-se a Putnam, o que não muda o fato de que essa afirmação vale para toda ou qualquer filosofia que se disponha a tal. Na conceituação de Hacking, um exemplo extraordinário de idealista como Kant consegue, ao mesmo tempo, ser tanto um idealista transcendental como um realista empírico. As faculdades estéticas de tempo e espaço não são exigidas pelo objeto - ainda que essa afirmação só possa ser feita determinando-se as relações desse objeto em uma estrutura espaço-temporal. A estética transcendental subjaz às coisas em si mesmas, tomando-as apenas segundo as faculdades da experiência possível. Se os objetos são reduzidos enquanto representações de fenômenos, sua percepção imediata não precisa dizer mais nada sobre sua realidade além de que são conhecimentos sintetizados por nossas faculdades do entendimento (HACKING, 2012, p. 173). 
Reduzir a representação a experiência possível ou, tal como o fez a filosofia contemporânea, a seu uso prático-operatório em uma linguagem que resguarde a objetividade de toda entidade verdadeira ou, tal como foi o esforço do positivismo lógico e o de Peirce, em identificar na probabilidade um recurso certo e regular (HACKING, 2012, p. 131) justamente pela admissão da insuficiência da representação em corresponder a algo que não esteja no âmbito do privado ou, em outras palavras (tal como raciocina o realismo interno de Putnam), exigir enquanto condição de verdade a correspondência absoluta entre as palavras e a totalidade fixa de objetos da mente (HACKING, 2012, p. 168) -, tudo isso são exigências que possuem relevância apenas enquanto teorias da verdade: se esse é o caso, i.e., se a realidade só pode fazer sentido se é referencial em sua totalidade, de fato a representação sempre será insuficiente. Todavia, afirma-lo nada diz de relevante nem sobre o uso prático das representações em um trabalho teórico interessado pelo Real, nem sobre o próprio procedimento científico, o que torna todo esse esforço estéril.

O realismo ontológico proposto por Hacking para superar essa esterilidade teórica deve determinar a verdade pelo que a realidade de fato é, ou, por assim dizer, a relação entre as entidades particularizadas pela teoria e a correspondência objetiva dessas entidades a ela. $\mathrm{O}$ elemento epistemológico justifica a verdade ontológica e portanto acessível. Tal componente ontológico é essencial à representação. Sendo assim, a perspectiva de articular as ciências como explicação dos fenômenos é sempre secundária; estes são forjados posteriormente ao intervir da perspectiva científica com o fim de explicar fenômenos mais gerais: uma ideia reguladora da totalidade das ciências é sempre uma ideia póstuma, se não já desnecessária de todo quando se contemplam os limites dessa perspectiva. Não é próprio ao realismo ontológico, portanto, explicar necessariamente a realidade tal como ela é; para isso, ele se utiliza de hipóteses. O antirrealista afirmaria que a experimentação para a formulação da hipótese é uma extensão da teoria: parte de uma noção que a realidade tal como ela é nos é alheia, voltando-se para os métodos de sua validação, como a linguística, a epistemologia e a própria teoria - justamente aquilo que na visão de Hacking se revela estéril.

Não há sentido em uma ciência que tente inferir no objeto com mínima intervenção possível (LECOURT, 2018, p. 137). A tendência dos positivistas lógicos foi utilizar da lógica para restringir sentenças teóricas, gerando um sistema de abreviação que organizasse o pensamento a respeito do que pode ou não pode ser observado (HACKING, 2012, p. 258) - o que é, por definição, um realismo insípido que se restringe ao observável. A intervenção, ainda que sem o suporte de uma expressão absoluta de uma teoria, 
nunca é aleatória (ou ao menos não o pode ser de todo), mas controlada, e a teoria contorna aquilo que não é dito imediatamente pelo sensível e pelos instrumentos. Para isso, a experimentação possui vida própria: uma objetividade na qual a realidade responde e nos é direcionada, contrária a todas as perspectivas antirrealistas que se possam ter da realidade como apenas extensão da teoria. A realidade não é alheia; ela só nos diz algo na medida em que se exigem dela respostas. O que ocorre na experimentação é a evocação de eventos que só poderiam ocorrer em casos excepcionais.

Em geral, a filosofia da ciência tem pouco caráter normativo nos métodos de proceder da ciência, e conduzir uma experimentação não precisa condizer necessariamente com uma linguística, doutrina ou teoria, desde que não seja aleatória, e sim monitorada pela própria natureza do experimento: o fenômeno não diz nada no fundo, mas pode dizer algo desde que sofra significação. $\mathrm{O}$ fenômeno só diz algo se é constituído em um regime entre representação subjetiva e semelhança autossuficiente na dimensão da própria comunicação (algo que ficará mais claro no tópico seguinte), tal que nos é acessível e geral, pois fenômeno, nesses termos, é algo público, semelhante a uma lei, digno de atenção e discernível. ${ }^{2}$ Concomitantemente a essa conclusão, experimentar é também criar, e é difícil produzi-los em formas usuais que não por meio da intervenção. É na restrição do fenômeno que ele sofre significação e dá sentido a uma teoria, e não o inverso.

Em um primeiro momento aparentemente uma noção muito distante ou mesmo superior da tradição, Hacking reconhece o realismo até então como usualmente discutido em termos de representação, da mesma forma como todas as objeções antirrealistas, que ainda se davam na esfera da redução da realidade a uma teoria nos moldes também do representar. A superação dessas perspectivas só poderia se dar em moldes intervencionistas: real é o utilizado para afetar o mundo de modo a gerar algo, ou algo gerado pelo mundo que nos afeta (HACKING, 2012, p. 231). Ainda assim, é inegável que toda ciência é afetada não só por representações distintas, mas por representações distintas de coisas iguais, que, por exigência da teoria, deveriam ter uma só representação que conviesse à sua verdadeira natureza (HACKING, 2012, p. 227).

Para explicitar essa perspectiva intervencionista que excede a exigência absoluta de representação, Hacking cita um exemplo relevante. Quando Heirich Hertz (1857-1894), em obra póstuma intitulada Princípios da mecânica, de 1894, apresenta três formas diferentes de

${ }^{2}$ MENDONÇA, A. L. O. Ian Hacking: uma ponte entre a tradição e a pós-modernidade. In: HACKING,

I. Representar e intervir: tópicos introdutórios em filosofia da ciência natural. Rio de Janeiro: EdUERJ, 2012. p. 12. 
representar o movimento dos corpos - em que há a qualificação de seus respectivos méritos, favorecendo-se, no fim, um dos três (HACKING, 2012, p. 227) -, as representações disponíveis, ainda que digam algo distinto uma da outra, sofrem a precisão do critério. A identificação de critérios é o que permite a representação correta das semelhanças. A metafísica, portanto, durante muito tempo adotou como problema a possibilidade de julgar as condições dos sistemas de representação; o que justamente torna o problema da metafísica válido é que o estabelecimento de critérios para a identificação de semelhanças na representação é interno à própria representação e, sendo assim, ao objeto intuído (HACKING, 2012, p. 226). Um critério de semelhança interno ao objeto intuído nos termos da evidência e da certeza e que não procure se desprender dele pode ser mais bem expresso na primazia que a intuição ganha em Kant em relação à metafísica anterior:

Aproximar-se do intuicionismo consiste, também desde os textos précríticos, em fazer dos axiomas geométricos paradigmas da evidência, assim como das demonstrações geométricas paradigmas da certeza [...]. Entre o intuicionismo e o formalismo, se Kant é capaz de formular uma versão inédita do primeiro, é porque jamais se é levado a imaginar, nem nos textos pré-críticos nem na $C R P$, um método universal cujos fundamentos se depreendem da geometria, como se imagina no Discurso do método. Jamais se é levado a supor uma ciência da ordem e da medida que, não se limitando a nenhum objeto, é aplicável a todos, quer quantitativos, quer qualitativos. Como ciência da medida, aos objetos sensíveis, extensos, mensuráveis; como ciência da ordem, aos suprassensíveis, inextensos, não mensuráveis. (CODATO, 2009, p. 199)

\section{O CREPÚSCULO DOS EMBATES ENTRE REALISMO E ANTIRREALISMO EM TERMOS DE REPRESENTAÇÃO [VORSTELLUNG]}

Muito do que se produz em filosofia da ciência está relacionado com a epistemologia do século XVII, atendo-se a uma teoria do conhecimento do espectador: tal é a forma enfática com que Hacking retoma a crítica de John Dewey (1859-1952). Se se é meramente expectador, tendo em vista apenas os conceitos teóricos do que se quer analisar, como então acessar a dita realidade? Somente na bem delineada distinção entre teoria e observação é possível garantir que se observa o real, em contraste a uma realidade presa à teoria. Admitir que toda observação tem por pressuposto uma teoria é ficar completamente atado à representação dela, recaindo-se em idealismo (HACKING, 2012, p. 211). É essa a razão de Hacking para questionar se não seriam todas as filosofias da ciência, até 
então, partes de uma teoria do conhecimento do espectador, ou, mais diretamente na fala de André Luís de Oliveira Mendonça:

Para a filosofia da ciência tradicional, que tomava a ciência teórica como o mais elevado padrão de racionalidade, ou como a mais bem-sucedida forma de conhecimento, em virtude de suas descrições corretas do mundo natural, nada poderia ser mais irônico ou soar mais provocativo do que o fato de a engenharia [...] ser a melhor arma contra o antirrealismo. (MENDONÇA, 2012, p. 34)

Ainda que a representação como critério epistêmico seja algo relevante para a validação da existência dos elétrons (CROTEAU, 2005, p. 59), o exemplo da história em torno de Bohr (1885-1962) e dos elétrons torna a discussão da representação muito mais explícita. Quando Johnstone Stoney (1826-1911) sugeriu a nomenclatura da unidade natural da eletricidade como "elétron" em 1891, ele apenas especulava a existência de uma unidade mínima da carga elétrica (HACKING, 2012, p. 157). É sabido que, concomitantemente às pesquisas de Stoney, J. J. Thomson (1856-1940) nomeava a carga mínima dos raios catódicos de corpúsculos, vendo nela a substância última das cargas. Lorentz (1853-1928) chegou às mesmas conclusões a respeito de uma partícula de carga mínima e a nomeou "elétron". Millikan (1868-1953) a mediu em 1908. Todas essas teorias e especulações se assimilaram em um mesmo trabalho experimental. Independentemente de Stoney estar falando ou não de elétrons tal como os compreendemos hoje, isso não faz a menor diferença, pois enquanto em sua pesquisa fazia os experimentos, eram os experimentos que lhe diziam a unidade natural da eletricidade, e não o fato de, partindo de uma teoria, nomeá-la e classificá-la. Qualquer movimento desse tipo é impossibilidade de reagir à novidade. Foi a determinação experimental da massa de partículas ultra-atômicas que definiu sua realidade: "Quando construímos dispositivos materiais, ou quando conhecemos outras entidades, supondo certas propriedades dos elétrons, isso seria um forte indício - ou mesmo uma comprovação - de que eles existem” (MENDONÇA, 2012, p. 157).

Para tornar a teoria um procedimento necessário, a realidade é entendida enquanto subproduto de um fato a respeito dos seres humanos. O realismo não pode ser tomado em termos de razão pura, nem de juízo, metafísica dos costumes e ciência natural; tendo em mente a terminologia de Kant, é necessário descrever o realismo como assunto que concerne à antropologia (HACKING, 2012, p. 213). 


\section{REGIME DE SEMELHANÇA: UM SUBSTITUTO PARA A REPRESENTAÇÃO}

Desde Descartes aquilo que faz dos homens o que são é a racionalidade, tomada enquanto capacidade discursiva e de fala. A despeito disso, Hacking propõe (em suas próprias palavras) uma fantasia com o objetivo de explicitar a indeterminação de uma conclusão sobre os embates do realismo e do antirrealismo em termos representativos: a proposta consiste na proposição de que os seres humanos são seres que representam. Não o homo faber de Aristóteles, mas o homo depictor: pessoas fazem representações, pois humanos são fabricantes de semelhança [likeness] (HACKING, 2012, p. 214). A semelhança, nos termos de Hacking, é a mais próxima de um nível puramente conceitual; em suma, é o produto de uma atividade representativa. A representação, portanto, é o que mais se aproxima do "conceito", justamente por Hacking excluir as representações [Vorstellungen] kantianas de sua definição de "representar" (HACKING, 2012, p. 215), ainda que "representar" denote colocar algo diante da mente (tanto imagens quanto pensamentos abstratos, substitutos para o termo “ideia”). Hacking nega a natureza reguladora da ideia, relegando o "conceitual" ao campo de termos de representação. Por conseguinte, toda representação é voltada para seu significado público (e tem por isso seu lastro nele) no que gera semelhança.

Retomando Kant, o juízo é a representação de uma representação: o colocar diante da mente (pôr, no idealismo alemão) de um colocar diante da mente, sendo duplamente privado - o "julgar como real de um julgar como real". Hacking nega o duplo que priva o real em seu sentido extraprivado. Aqueles que são mais publicamente reconhecível são o visual e o tátil, e as representações mais antigas das civilizações geralmente procedem desses níveis. Os homens possuem a faculdade de ver, mas não é por terem olhos que representam semelhanças, e os olhos não são essência (enquanto faculdade de ver), mas ferramentas para uma semelhança passível de ser adquirida e pré-existente em seu sentido público. Assim, tal semelhança só se concretiza em seu uso público. Como a semelhança é produto da atividade de representar, ela não é algo que se dá internamente nem relativamente; a semelhança, por isso, não é uma faculdade, mas, por se dar em seu uso geral, é extraprivada e ganha caráter antropológico. A representação é sempre, a princípio, aquilo que expressa uma semelhança pública e pré-existente.

A semelhança, em termos gerais, é o produto de uma atividade representativa do entendimento, e tal semelhança expressa por si só uma 
semelhança pública, cuja representação abstrai e torna ente. Teorias, e não sentenças individuais, são representações. Representar é também alegar em favor, em sentido afirmativo. Todas essas proposições, sintetizadas quando Hacking cita William James (18421910), referem-se com desprezo àquilo que é denominado na tradição como verdade enquanto correspondência (HACKING, 2012, p. 215). Partindo da representação em termos agora antropológicos, entende-se aqui por regime de semelhança, termo nosso, a relação necessária e intrínseca entre a representação e a semelhança autossuficiente, sempre anterior ao ser semelhante particular, mas compreendida em sua inteireza apenas postumamente na intelecção reflexiva da ação afirmativa do representar. Em outras palavras, ainda que a semelhança seja anterior à ação afirmativa do representar e independa de qualquer conceito, ela só pode ser plenamente compreendida ulteriormente, tornando-se necessário que seja produto das atividades representativas, ainda que seja, por natureza, anterior.

Tal regime não é produto anterior à linguagem ou, como se poderia dizer, a priori, mas ulterior, de maneira que a racionalidade humana é consequência da comunicação nesse regime de semelhança: o sozinho não é racional (por exemplo, loucos falam consigo mesmos), apenas o é na medida em que representa e gera semelhança; o gênio não é gênio para si mesmo, mas só o é em referência àquilo em que ele excede o medíocre. A linguagem é apêndice da racionalidade (pois é certo que anteriormente a uma linguagem formal já havia semelhança), e os humanos, ao desenvolverem uma linguagem, se tornaram, por fim, racionais (HACKING, 2012, p. 217). A essência racional é consequência de um regime de semelhança desvelada pela representação próprio à natureza humana. Sou homem: nenhum assunto humano julgo alheio a mim [homo sum: humani nil a me alienum puto $]^{3}$.

A realidade, nesse sentido, é uma representação antropomórfica, pois exige algo de real de nós mesmos a respeito daquilo que representamos. A realidade é de segunda ordem, e não uma referência exigida imediatamente no ato de representar (percepção afirmativa). $\mathrm{O}$ representar da realidade só é criado quando já se tem por princípio a representação em um regime de semelhança - nunca algo imediato, mas produto ulterior daquele. O lugar do mundo, por conseguinte, vem em terceiro, uma vez que se julga a representação enquanto algo real. O representar do mundo é atributo testamentário das representações - o mundo enquanto representação é arbítrio de representações e semelhante ao fluxo do pensamento de Descartes: é lastro ulterior para se atribuir qualidade factual às representações anteriores. Nesse sentido, a racionalidade estatística é uma eficiente ferramenta, por lidar com

\footnotetext{
${ }^{3}$ Sobre a tradução, cf. ROSSI, 2011, p. 15.
} 
padrões a princípio aleatórios de sucessões de eventos padronizados por uma sequência necessária. Essa modalidade se torna um padrão nas ciências em geral. A estatística representa bem padrões de semelhanças.

É dito que as coisas, se semelhantes, devem obedecer a alguma qualidade que as torna comuns. Para se explicitar a semelhança, é preciso um conceito dela. Em Hacking, termos de semelhança não antecedem a semelhança. Coisas podem ser simplesmente semelhantes sem que essa semelhança tenha de ser especificada por alguma qualidade conceitual que as torne comuns, pura e simplesmente porque regimes de semelhança não obedecem a essas qualidades. Enquanto representações objetificadas, elas são por si mesmas constitutivas do entendimento, tendo por princípio o fato de que humanos produzem semelhanças: as representações obedecem a essas exigências, e não às do conceito, pois atribuir importância maior ao conceito é exigir que todas as coisas, incluindo-se obviamente todo o regime de semelhança, obedecem não ao sentido público, mas a exigências conceituais independentes desse sentido, que deve se adequar, por definição, ao conceito.

O entendimento reconhece as semelhanças não pelo que representam, mas por serem parâmetro de representações humanas, e no reconhecimento há semelhança: a semelhança é o lastro da validade do conhecimento. As representações se assemelham àquilo que representam segundo uma forma mais primordial de semelhança. É possível não entender nada sobre determinado sistema de representação, tal como idiomas que nos são estranhos e arabescos, mas ainda assim ser capaz de reconhecer suas representações enquanto representações de algo, regime de semelhança imediatamente identificável enquanto sistema em uma representação (HACKING, 2012, p. 220).

Uma representação é cognoscível mesmo que não seja possível responder a ela adequadamente. Disso se conclui que as representações não servem para nos dizer como as coisas realmente são, de tal maneira que a semelhança não chega a envolver uma relação, pois é anterior ao ser semelhante, sendo por si só autossuficiente. A semelhança não se restringe ao particular que lhe é semelhante, e o semelhante é regime de semelhança na medida em que imediatamente representa a autossuficiência do ser semelhante, condição para qualquer juízo de real. A semelhança, por conseguinte, independe da mediação de conceitos por brotar do puro processo afirmativo do ato de representar. Todas as representações têm algo em comum, pois em todas há algo de humano, e ser humano é ser enquanto fabricador de semelhanças. Esse algo em comum e autossuficiente que cria os termos da relação é anterior ao ser semelhante representado. 


\section{CONSIDERAÇÕES FINAIS}

A representação em termos epistemológicos certamente tem uma primazia cuja contestação não é propriamente nosso enfoque, mas constatamos, tal como colocado por Hacking, que é somente na assimilação que se geram conceitos os quais assimilam a representação em um sentido coeso e sistêmico, pois a semelhança independente do conceito, trazendo a representação não para o lar epistêmico, mas para o nível antropológico. Em suma, o conceito é sempre póstumo, fruto do entendimento de uma semelhança que independente de qualquer conceituação, pois é enquanto representação.

A semelhança brota do processo afirmativo do representar e nisso ela é primordial, ainda que não venha primeiro, por sua natureza passiva, afirmativa apenas enquanto representação. É no desenvolvimento das técnicas de que dispomos e na disposição dos materiais que o homem encontra outros meios de representar, para nisso identificar o que é exatamente semelhante a o quê (HACKING, 2012, p. 222). A representação abstrai o semelhante em conceitos que lhe são póstumos, e neles revela sua natureza pública e cognoscível no entendimento: a intervenção empírica que reconhece o real enquanto mundo tem por fundamento o lastro próprio de um regime de semelhança daquele semelhante geral e autossuficiente intrínseco à natureza humana.

Colocando o real apenas como proposição inocente daquilo que há em nós mesmos enquanto representamos, "realidade" ou sua negação perdem seu sentido em termos de representação [Vorstellung] do fenômeno, para fazer sentido apenas enquanto algo constitutivo de nossa própria natureza. Representar é o produto natural de uma semelhança, fato antropológico que, além de seus limites, nada mais diz que não seja limitado a um regime. Real é o que afeta e o que responde, que não se limita, e apenas no uso da intervenção empírica o realismo científico tem algo a dizer que não seja voltar a si mesmo. 


\section{REFERÊNCIAS}

ARENDT, Hannah. Entre o passado e o futuro. 8. ed. São Paulo: Perspectiva, 2018.

BRANQUINHO, João; MURCHO, Desidério; GOMES, Nelson Gonçalves. Enciclopédia de termos lógico-filosóficos. São Paulo: WMF Martins Fontes, 2005.

CODATO, L. (2009). Descartes em Kant. Discurso, 39 (39), p. 195-222. Disponível em: <https://doi.org/10.11606/issn.2318-8863.discurso.2009.68268>. Acesso em 22 de novembro de 2018.

CROTEAU, Jonathan Beaudet. Podemos fazer ciência sem teorias? Um estudo sobre o realismo de entidades \& o anti-realismo de teorias de Hacking e Cartwright. 2005. 150f. Dissertação (Mestrado em Filosofia) - Programa de Pós-Graduação em Filosofia, Universidade Federal de Santa Catarina, Florianópolis, 2005.

FORLIN, Enéias. A teoria cartesiana da verdade. São Paulo: Associação Editorial Humanitas; Ijuí: Editora Unijuí/Fapesp, 2005. (Coleção Filosofia, 14)

GUÉROULT, Martial. Descartes segundo a ordem das razões. Trad. César Augusto Battisti et al. São Paulo: Discurso Editorial, 2016.

HACKING, Ian. Representar e intervir: tópicos introdutórios em filosofia da ciência natural. Rio de Janeiro. Eduerj. 2012.

KANT, Immanuel. Crítica da razão pura. 8 edição. Trad. Manuela Pinto dos Santos e Alexandre Fradique Morujão. Lisboa: Fundação Calouste Gulbenkian, 1997.

KOYRÉ, Alexandre. Considerações sobre Descartes. 3 ed. Lisboa: Editora Presença, 1992.

Estudos de história do pensamento científico. Tradução e revisão técnica de Márcio Ramalho. Rio de Janeiro: Ed. Forense Universitária; Brasília: Ed. Universidade de Brasília, 1982.

LECOURT, Dominique. A filosofia das ciências. Aparecida: Ideias \& Letras, 2018.

MENDONÇA, A. L. O. Ian Hacking: uma ponte entre a tradição e a pós-modernidade. In: HACKING, Ian. Representar e intervir: tópicos introdutórios de filosofia da ciência natural. Rio de Janeiro: EdUERJ, 2012.

ROSSI, Gabriel. Heautontimorumenos de terêncio: a persona multiface de Cremes; 2011. Trabalho de Conclusão de Curso (Graduação em Estudos Literários) Universidade Estadual de Campinas; Orientador: Isabella Tardin Cardoso. 